\title{
P-Cadherin Promotes Liver Metastasis and Is Associated with Poor Prognosis in Colon Cancer
}

\author{
Lichao Sun, ${ }^{*}$ Hai Hu, ${ }^{*}$ Liang Peng, ${ }^{*}$ Zhuan Zhou, ${ }^{*}$ \\ Xuan Zhao, ${ }^{*}$ Jian Pan, ${ }^{*}$ Lixin Sun, ${ }^{*}$ Zhihua Yang, ${ }^{\dagger}$ \\ and Yuliang Ran* \\ From the State Key Laboratory of Molecular Oncology* and the \\ Department of Cell and Molecular Biology, ${ }^{\dagger}$ Cancer Institute \\ (Hospital), Chinese Academy of Medical Sciences, Peking Union \\ Medical College, Beijing, China
}

P-cadherin belongs to the family of classic cadherins, which is important for maintaining cellular localization and tissue integrity. Recently, it has become evident that $P$-cadherin contributes to the oncogenesis of many tumor types, including melanoma, prostate, breast, and colon carcinomas. Although cadherin switching is a crucial step in metastasis, the role of P-cadherin in colon cancer metastasis to the liver is unknown. In this study, we performed gene expression analysis and found that the level of P-cadherin was higher in tissue from liver metastases of colon cancer than in the corresponding primary colon cancer tissues. IHC analysis also showed that P-cadherin expression was significantly higher in liver metastases than in paired primary colorectal cancer tumors. Knockdown of P-cadherin in colon cancer cells inhibited wound healing, proliferation, and colony formation and resulted in developing fewer liver metastatic foci and reducing the tumor burden in vivo. Inhibition of P-cadherin expression also induced the upregulation of E-cadherin and the down-regulation of $\beta$-catenin and its downstream target molecules, including survivin and c-Myc. In summary, these results uncover a novel function of $P$-cadherin in the regulation of colon cancer metastasis to the liver, suggesting that blocking the activity of P-cadherin or its associated signaling may be a valuable target for the treatment of hepatic metastases of colon carcinomas. (Am J Pathol 2011, 179:380-390; DOI: 10.1016/j.ajpath.2011.03.046)

Colon cancer is one of the most common cancers in the world and has a high propensity for liver metastasis. ${ }^{1,2}$ The primary cause of death in patients with colon cancer is liver metastasis, ${ }^{3}$ and 5 -year overall survival is only $25 \%$ to
40\%. ${ }^{3,4}$ Early treatment targeting colon cancer liver metastatic foci might be important for improving patient survival. Therefore, there is an urgent need to identify molecules that facilitate the metastasis of colon cancer to the liver, which would be potential therapeutic targets for treating patients with colon cancer and liver metastases.

Cancer metastasis is a complex process involving many genes that function in the tumor cell and at the target organ. ${ }^{5,6}$ In the past, gene array technology has been used to identify different genes relevant to cancer metastasis. ${ }^{7}$

P-cadherin, one of the classic cadherins, has an extracellular N-terminal domain, a transmembrane domain, and a cytoplasmic carboxy-terminal domain. The cytoplasmic domain of the classic cadherins binds the catenin family members. ${ }^{8}$ The cadherin-catenin interactions are necessary to maintain the cell-cell adhesion function of the cadherin complex. ${ }^{9,10}$ Accumulating evidence shows that perturbation of P-cadherins is strongly associated with carcinogenesis and confers malignant phenotype on cancer cells. ${ }^{11-13}$ For example, overexpression of $\mathrm{P}$-cadherin is likely to be related to the biologic aggressiveness in pancreatic carcinoma. ${ }^{14}$ Similarly, up-regulation of P-cadherin could promote bladder carcinoma cell migration and be associated with a poor clinical outcome and prognosis. ${ }^{15}$ Although P-cadherin contributing to colon cancer progression has been reported, ${ }^{2}$ the role of P-cadherin in the metastasis of colon cancer to liver has not been explored.

In this study, we performed CDNA microarray and $\mathrm{IHC}$ analysis and identified that P-cadherin was significantly as-

Supported by the National Key Basic Research Program of China (2009CB521804)

Accepted for publication March 2, 2011.

Supplemental material for this article can be found at $h$ ttp://ajp. amjpathol.org or at doi: 10.1016/j.ajpath.2011.03.046.

Address reprint requests to Yuliang Ran, Ph.D., State Key Laboratory of Molecular Oncology, Cancer Institute (Hospital), Chinese Academy of Medical Sciences, Peking Union Medical College, No.17 Panjiayuan Nanli, Chaoyang District, Beijing 100021, People's Republic of China; or Zhihua Yang, B.A., Department of Cell and Molecular Biology, Cancer Institute (Hospital), Chinese Academy of Medical Sciences, Peking Union Medical College, No.17 Panjiayuan Nanli, Chaoyang District, Beijing 100021, People's Republic of China. E-mail: ran_yuliang@yahoo.com.cn or yang_zhihua_prof@yahoo.com.cn. 
sociated with liver metastasis. Then, we investigated the role of P-cadherin in colon cancer liver metastasis in vivo and in vitro. These results, for the first time, imply that Pcadherin plays a key role in colon cancer hepatic metastasis.

\section{Materials and Methods}

\section{Reagents and Cell Lines}

The colon cancer cell lines LoVo, Colo205, and Ls174T were cultured in RPMI 1640 medium supplemented with $10 \%$ fetal bovine serum and $100 \mathrm{U} / \mathrm{mL}$ of penicillin/streptomycin (all from Invitrogen, Carlsbad, Ca). The colon cancer cell lines Colo320DM, SW480, SW620, Ls180, SW1116, HT29, and Hct1116 were maintained in Dulbecco's modified Eagle's medium (Invitrogen) supplemented with $10 \%$ fetal bovine serum and $100 \mathrm{U} / \mathrm{mL}$ of penicillin/ streptomycin (Invitrogen). Anti-P-cadherin antibodies were purchased from BD Biosciences (Franklin Lakes, $\mathrm{NJ}$ ). Anti- $\beta$-catenin, anti-survivin, anti-cyclin D1, and anti-E-cadherin antibodies were purchased from Santa Cruz Biotechnology (Santa Cruz, CA). Anti-vimentin, antisnail, anti-slug, anti-C-Myc, anti-C-Jun, and anti-N-cadherin antibodies were purchased from Cell Signaling Technology Inc. (Beverly, MA). Anti-p120-catenin antibodies were purchased from Epitomics Inc. (Burlingame, CA). Horseradish peroxidase-conjugated anti-rabbit and anti-mouse antibodies were obtained from Jackson ImmunoResearch Laboratories Inc. (West Grove, PA). Anti$\beta$-actin monoclonal antibodies were purchased from Sigma-Aldrich Corp. (St. Louis, MO). Lipofectamine 2000 was obtained from Invitrogen.

\section{Transfection}

Two small-interfering RNAs based on the P-cadherin sequences (5'-GGAGACAGGCTGGTTGTTG-3' and 5' CAUAUGACGUGCACCUUUC-3') were synthesized by RiboBio Inc. (Guangzhou, China). For stable knockdown of P-cadherin, the oligoduplexes were cloned into psiTarget 2.0-CMV-RFP-Neo siRNA vector (GeneChem, Shanghai, China) and were transfected into cells using Lipofectamine 2000 (Invitrogen). Transfected cells were selected by 500 $\mu \mathrm{g} / \mathrm{mL}$ of G418 for 2 weeks. Resistant clones were picked for expansion and characterization. P-cadherin expression was determined by Western blot and RT-PCR. Cells stably expressing short hairpin P-cadherin were designated as P-cadherin short hairpin RNA (shRNA) cells. Negative control cell lines were generated by infecting cells with a psiTarget 2.0-CMV-RFP-Neo vector construct targeting enhanced red fluorescent protein cDNA.

\section{Microarray Analysis of Tissues from Primary Colon Cancer and Paired Liver Metastases}

The microarray experimental procedures were described previously. ${ }^{16,17}$ The Human Genome Oligonucleotide Set (Version 2.1), consisting of $5^{\prime}$-amino acid-modified 70mer probes and representing 21,329 well-characterized
Homo sapiens genes, was purchased from QIAGEN $\mathrm{GmbH}$ (Hilden, Germany) and was printed on aminosilane-coated glass slides. Total RNA from primary colon cancer and liver metastasis samples was prepared for probing and then was hybridized using a human genomic 70-mer oligonucleotide microarray obtained from CapitalBio Corp. (Beijing, China). Five micrograms of DNase-treated total RNA was prepared, and fluorescent dye (Cy5 and Cy3-dCTP)-labeled cDNA was produced using Eberwine's linear RNA amplification method and subsequent enzymatic reaction. The cDNAs were then hybridized to an array. Arrays were scanned using a confocal LuxScan scanner, and the images obtained were analyzed using LuxScan 3.0 software (CapitalBio Corp.). Then, space- and intensity-dependent normalization based on LOWESS in the $\mathrm{R}$ language package (http://www.R-project.org, last accessed November 28, 2009) was used to normalize the two-channel ratio value. Candidate genes for liver metastasis were first extracted using a specified algorithm: significance analysis of microarrays (http://www-stat.stanford.edu/ tibs/SAM, last accessed December 3, 2009), which can statistically extract and quantify differences in gene expression between two groups. For this study, a fold change $>1.5$ and $q<0.05$ were used to identify genes that may promote liver metastasis.

\section{Patients and TMAs}

The tissues samples were from the Cancer Institute (Hospital), Chinese Academy of Medical Sciences and Peking Union Medical College (Beijing, China). All the studies were preapproved by the Institutional Review Board, and informed consent forms were signed by all the study participants. We enrolled patients with colon cancer with or without liver metastasis, and patients with colon cancer and other organ involvement were not included in this study. Colorectal cancer cases with no history of liver metastasis were designated M0 (96 cases); those with a history of liver metastasis were designated M1 (106 cases). TMAs were prepared from archival formalin-fixed, paraffin-embedded tissue blocks. For each tumor, a representative tumor area was carefully selected from an H\&E-stained section. A total of 202 specimens were placed on the TMA. For each case, normal tissues were repeated twice and cancer tissues were repeated five times. Clinical follow-up records are available for all the samples. In addition, we collected 30 colon cancer specimens with paired liver metastases for testing the expression of P-cadherin by immunohistochemical (IHC) analysis and RT-PCR.

\section{IHC Analysis}

The avidin-biotin complex method was used for $\mathrm{IHC}$ analysis. Briefly, after deparaffinization in xylene and graded alcohols, heated antigen retrieval was performed in citrate buffer (10 mmol/L, pH 6.0) by water bath kettle heating for 30 minutes. Next, endogenous peroxidase activity was blocked by incubating samples in $0.3 \%$ hydrogen peroxide for 10 minutes. Then, nonspecific binding was blocked by incubating samples in $10 \%$ normal animal 
serum for 10 minutes. Next, sections were incubated with primary antibodies against P-cadherin (610228, BD Biosciences), 1:50; E-cadherin (sc-7870, Santa Cruz Biotechnology), 1:200; and $\beta$-catenin (sc-7963, Santa Cruz Biotechnology), $1: 100$, at $4^{\circ} \mathrm{C}$ for 24 hours. Next, biotinylated secondary antibodies and horseradish peroxidase-labeled avidin were incubated with samples. Color was developed using the diaminobenzidine method. Expression analysis of proteins in malignant and epithelial cells was performed by comparing staining intensity and the percentage of immunoreactive cells. Staining intensity was arbitrarily scored on a scale of four grades: 0 (no staining of cancer cells), 1 (weak staining), 2 (moderate staining), and 3 (strong staining), and the percentage of positive cells was scored as follows: $0(0 \%), 1(1 \%$ to $25 \%), 2$ (26\% to $50 \%$ ), and 3 (>50\%). P-cadherin and E-cadherin staining positivity was determined using the following formula: overall score = positive percentage score $x$ intensity score. A score of 0 was defined as " 0 ," $>0$ to $\leq 2$ as " 1 ," $>2$ to $\leq 6$ as " 2 ," and $>6$ to $\leq 9$ as " 3 ." In the end, colon cancer samples rated as level 0 or 1 were defined as negative for expression, whereas samples rated as level 2 or 3 were defined as positive.

For the evaluation of $\beta$-catenin immunoreactivity, nuclear staining of malignant cells was regarded as positive, regardless of cytoplasmic staining. Immunostained sections were classified into two groups based on the proportion of positively stained tumor cells that had positive nuclear staining in the lesion: 0 (negative or positive but in $\leq 10 \%$ of tumor cells) versus 1 (positive in $>10 \%$ of tumor cells). Negative controls were performed by omitting the primary antibody. Blinded analysis of the slides was performed by two independent observers.

\section{Western Blot Analysis}

For immunoblots, cellular protein lysates were prepared in radioimmunoprecipitation assay buffer, resolved on SDS-PAGE gels, and transferred to nitrocellulose membranes. The transferred proteins were visualized using enhanced chemiluminescence immunoblotting reagents (Amersham Biosciences Corp., Sunnyvale, CA). A negative control was performed to ensure the specificity of immunostaining by replacing primary antibody with a nonimmune mouse or rabbit IgG.

\section{Wound-Healing Assay}

Cells were grown to $95 \%$ confluency in a 6 -well plate. A wound was created by scratching cells with a sterile 200- $\mu \mathrm{L}$ pipette tip. Cells were washed three times with serum-free medium to remove the floating cells, and fresh serum-free culturing medium was added. Photographs of the wound were taken under $\times 10$ magnification.

\section{Cell Proliferation Assay}

Cells were trypsinized and resuspended in complete medium and were seeded equally into 96-well plates. Cells were counted using Cell Counting Kit-8 (Dojindo Molecular Technologies Inc., Rockville, MD) at the indicated time points according to the manufacturer's instructions, and optical density was measured at $450 \mathrm{~nm}$. These experiments were performed twice with similar results.

\section{Colony Formation Assay}

To study anchorage-independent growth, six-well plates were layered with $1.5 \mathrm{~mL}$ of $0.5 \%$ agarose in Dulbecco's modified Eagle's medium with 10\% fetal bovine serum and penicillin-streptomycin. Subsequently, 1000 cells mixed with $0.35 \%$ agarose were set in each well of the six-well plates to form the upper gel. After 2 weeks, pictures of colonies were taken using a digital camera after staining with $0.005 \%$ blue violet. Each treatment was performed in triplicate. Colony numbers were counted at least twice, and the data were imported into Excel spreadsheet software (Microsoft Corp., Redmond, WA) for graphing and statistical analysis.

\section{Immunofluorescence}

Cells were cultured for 24 hours. After rinsing with PBS, cells were fixed in PBS-4\% paraformaldehyde for 30 minutes and were permeabilized with $0.1 \%$ Triton X-100 (Roche Diagnostics GmbH, Mannheim, Germany) for 10 minutes at $4^{\circ} \mathrm{C}$. Cells were then incubated with P-cadherin (1:50), $\beta$-catenin (1:100), and p120-catenin (1:200) primary antibodies, followed by Cy3-conjugated antimouse IgG (1:200) or fluorescein isothiocyanate-conjugated anti-rabbit IgG (1:300) secondary antibodies. Samples were then mounted onto slides and were visualized using a confocal microscope (Leica Microsystems $\mathrm{GmbH}$, Wetzlar, Germany).

\section{Animal Experiments}

All the animal experiments were performed in full compliance with institutional guidelines and with the approval of the Animal Care and Use Committee, Cancer Institute (Hospital), Chinese Academy of Medical Sciences and Peking Union Medical College. Female nu/nu mice, obtained from The Jackson Laboratory (Vital River Laboratories, Beijing, China), were kept in a pathogen-free facility at the Experimental Center of the Chinese Academy of Medical Sciences. The facility is accredited for animal care by the Chinese Association for Accreditation of Laboratory Animal Care. For experimental liver metastases, model LoVo clones stably transfected with two shRNAs targeting distinct P-cadherin sequences or vector were harvested and resuspended in PBS at a final concentration of $2 \times 10^{7}$ cells $/ \mathrm{mL}$. Mice were anesthetized by i.p. injection of pentobarbital (60 mg/kg). Using a 10-mm left subcostal incision, the spleen was identified beneath the peritoneum and was exposed via an $8-\mathrm{mm}$ peritoneal incision. A suspension of tumor cells (100 $\mu \mathrm{L})$ was injected into the spleen using a 27-gauge needle, after which the spleen was returned to the abdominal cavity. The peritoneum was sutured with a single stitch, and the wound was closed using a clip. Mice were sacrificed 8 weeks after tumor cell inoculation. The liver with metastasis foci was used for pathologic confirmation of the liver 
Table 1. Genes Up-Regulated in the Liver Metastatic Tissues and Gene Ontology Categories

\begin{tabular}{|c|c|c|c|c|c|c|c|}
\hline Gene name & RefSeq & $\begin{array}{l}\text { Mean } \\
\text { ratio }\end{array}$ & $\mathrm{CV}$ & Score $(d)$ & q value $(\%)$ & Function & Description \\
\hline IGFBP1 & NM_000596 & 13.19 & 0.04 & 19.34 & 0.00 & Proliferation & $\begin{array}{l}\text { Insulin-like growth factor binding protein } \\
1 \text { precursor }\end{array}$ \\
\hline RPA3 & NM_002947 & 1.77 & 0.08 & 3.66 & 3.98 & DNA repair & Replication protein A 14 kd subunit \\
\hline P-cadherin & NM_001793 & 1.78 & 0.09 & 3.65 & 3.98 & Adhesion & Cadherin-3 precursor \\
\hline HRMT1L3 & NM_005788 & 2.06 & 0.09 & 4.57 & 1.41 & Metabolism & Protein arginine $\mathrm{N}$-methyltransferase 3 \\
\hline SCARB1 & NM_005505 & 2.17 & 0.18 & 3.76 & 3.21 & Metabolism & Scavenger receptor class B member 1 \\
\hline ADFP & NM_001122 & 2.69 & 0.24 & 4.29 & 2.03 & Metabolism & Adipophilin \\
\hline COLEC11 & NM_024027 & 9.85 & 0.38 & 6.35 & 0.00 & Metabolism & Collectin subfamily member 11 isoform \\
\hline TM4SF4 & NM_004617 & 21.80 & 0.38 & 8.55 & 0.00 & Proliferation & Transmembrane 4 superfamily member 4 \\
\hline HPR & NM 020995 & 10.17 & 0.43 & 5.90 & 0.41 & Metabolism & Haptoglobin-related protein precursor \\
\hline$F G B$ & NM_005141 & 25.02 & 0.48 & 6.98 & 0.00 & Proliferation & Fibrinogen beta chain precursor \\
\hline SERPINA3 & NM_001085 & 22.72 & 0.58 & 5.58 & 0.41 & Metabolism & Alpha-1-antichymotrypsin precursor \\
\hline$C R P$ & NM_000567 & 73.84 & 0.65 & 9.24 & 0.00 & $\begin{array}{l}\text { Acute-phase } \\
\text { response }\end{array}$ & C-reactive protein precursor \\
\hline DEFB1 & NM_005218 & 7.20 & 0.65 & 3.57 & 3.98 & $\begin{array}{l}\text { Innate immune } \\
\text { response }\end{array}$ & Beta-defensin 1 precursor \\
\hline$A P O B$ & NM_000384 & 22.07 & 0.68 & 5.46 & 0.41 & Metabolism & Apolipoprotein B-100 precursor \\
\hline$A L B$ & NM_000477 & 45.87 & 0.70 & 4.18 & 2.03 & Metabolism & Serum albumin precursor \\
\hline APCS & NM_001639 & 40.25 & 0.75 & 6.08 & 0.41 & Metabolism & Serum amyloid P-component precursor \\
\hline FMO3 & NM_001002294 & 17.57 & 0.76 & 4.76 & 0.86 & Transport & Dimethylaniline monooxygenase \\
\hline APOA1 & NM_000039 & 23.95 & 0.80 & 4.48 & 1.41 & Metabolism & Apolipoprotein A-I precursor \\
\hline CYP2E1 & NM_000773 & 15.53 & 0.83 & 3.66 & 3.98 & Metabolism & Cytochrome P450 2E1 \\
\hline APOC3 & NM_000040 & 18.50 & 0.85 & 3.79 & 3.21 & Metabolism & Apolipoprotein C-III precursor \\
\hline WDHD1 & NM_007086 & 19.21 & 0.89 & 3.51 & 4.80 & Transcription & $\begin{array}{l}\text { WD repeat and HMG-box DNA binding } \\
\text { protein } 1\end{array}$ \\
\hline ORM1 & NM_000608 & 27.33 & 0.91 & 3.93 & 3.21 & $\begin{array}{l}\text { Acute-phase } \\
\text { response }\end{array}$ & Alpha-1-acid glycoprotein 2 precursor \\
\hline
\end{tabular}

$\mathrm{CV}$, coefficient variation.

metastasis. For tumor formation assay, LoVo P-cadherin shRNA cells, vector cells, or Ls174T P-cadherin shRNA cells were subcutaneously injected into nude mice with $1 \times 10^{6}$ cells per animal for each group. Forty-three days after injection, 24 mice were sacrificed, and invasive patterns were analyzed using H\&E staining.

\section{Statistical Analysis}

The SPSS, version 15, software package (SPSS Inc., Chicago, IL) was used for statistical analysis. The two-sided $t$-test method was used for analysis of the number of mouse liver metastatic foci among groups. The association between the immunoreactive markers and the clinicopathologic features was analyzed using the $\chi^{2}$ test or the two-sided $t$-test, as appropriate. The survival rates were assessed by the Kaplan-Meier method and compared by the log-rank test. A $P<0.05$ was considered statistically significant.

\section{Results}

\section{Microarray Analysis}

To acquire genes associated with colon cancer liver metastasis, we evaluated gene expression in primary and metastatic samples using the CapitalBio Corp. human genomic 70-mer oligonucleotide microarray. ${ }^{18}$ Gene array analysis revealed that there were 677 genes with significantly different expression, including 22 that were up-regulated and 655 that were down-regulated in the metastatic tissue. We focused on the genes that were up-regulated in the colon cancer liver metastatic samples (Table 1). Of the 22 up-regulated genes, 4 candidate genes, including IGFBP1, ${ }^{19}$ HPR, ${ }^{20}$ CYP $2 E 1,{ }^{21}$ and $P$ cadherin, ${ }^{22}$ which are involved in metabolism, proliferation, and adhesion and are closely associated with cancer metastasis, were selected for further study. To confirm the microarray data, we performed semiquantitative RT-PCR and tested four candidate genes in four fresh paired primary and metastatic samples. The housekeeping gene GAPDH was used as a reference. P-cadherin was consistently up-regulated in liver metastasis samples compared with primary colon cancer samples, whereas other genes were highly expressed in a portion of the samples (Figure 1A). The results suggest that Pcadherin is associated with colon cancer liver metastasis.

\section{IHC Analysis}

To determine whether the observed up-regulation of $\mathrm{P}$ cadherin is a common feature of colon cancer liver metastasis, we evaluated the expression of P-cadherin in 30 primary colon cancer samples and paired liver metastatic samples. We found that among these 30 paired samples, P-cadherin was positive in 29 primary tumors $(96.7 \%)$ and in 22 corresponding liver metastases (73.3\%). The expression of $\mathrm{P}$-cadherin in the hepatic metastases was noticeably higher than that in the matched primary colon cancer tissues. T-test analysis revealed that the levels of P-cadherin were significantly higher in the liver metastasis tissues than in the primary tissues (Figure 1B). To 

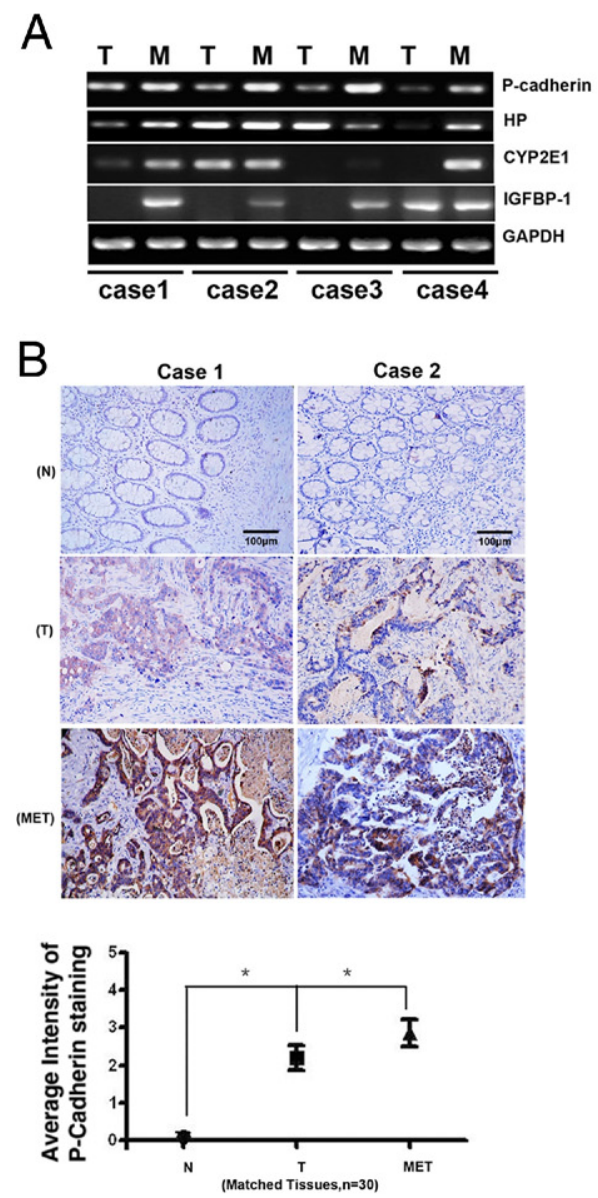

C

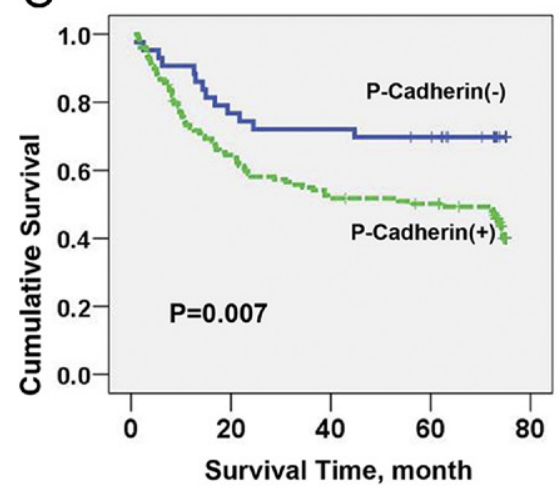

Figure 1. Expression of P-cadherin in human primary colon carcinomas and liver metastatic tissues. A: A higher level of P-cadherin mRNA was found in liver metastatic tissues $(\mathrm{M})$ than in matched primary colon tumor (T) from the same patient. B: IHC analysis of P-cadherin expression in primary (N and T) and metastatic (MET) colon cancers. Results are shown as means \pm SD Statistical significance of ${ }^{*} P<0.05$. C: Kaplan-Meier curves showing the survival of patients with colon cancer with P-cadherin staining. P-cadherin overexpression correlates with a poor prognosis in patients with colon cancer. Statistical significance of ${ }^{*} P<0.05$, log-rank test.

further analyze the clinical correlation of colon cancer with P-cadherin expression, we evaluated its expression in a colon carcinoma TMA containing 202 primary colon tumors. There was no detectable staining of P-cadherin in the normal epithelium, but 153 of 202 primary lesions exhibited positive staining. In addition, there were approxi- mately 98 cases containing tumor invasion front. IHC scoring showed that 69 of 98 of the primary lesions exhibited positive staining for P-cadherin. Statistical analysis also indicated that P-cadherin expression in colon cancer was correlated only with liver metastasis $(P<0.05)$, and there was no significant association with other clinicopathologic variables (Table 2). The prognostic significance of P-cadherin was determined by P-cadherin staining and the corresponding clinical follow-up records. Kaplan-Meier survival analysis revealed a correlation between higher P-cadherin expression levels and shorter overall survival times $(P<0.05)$ (Figure 1C). Taken together, these observations indicate that overexpression of $P$-cadherin is significantly associated with colon cancer liver metastasis and poor prognosis in patients with colon cancer.

\section{Knockdown of P-Cadherin in LoVo and Ls174T Cells}

It has been reported that perturbation of cadherin expression could affect cell function ${ }^{23}$; therefore, we first evaluated the levels of P-cadherin, E-cadherin, and N-cadherin mRNA in 10 colon cancer cell lines cultured in the State Key Laboratory of Molecular Oncology. The result showed that P-cadherin mRNA levels were relatively high in 8 of 10 cell lines, excluding Colo320DM and SW620. E-cadherin mRNA levels in colon cancer cell lines were relatively low, and they were undetectable in Colo320DM, LoVo, and Ls174T. Similarly, we could not detect N-cadherin mRNA in the colon cancer cell lines except SW1116, Hct1116, Ls180, and HT29 (Figure 2A). Thus, it seems that the overexpression of $\mathrm{P}$-cadherin is a preva-

Table 2. Clinicopathologic Characteristics of the 202 Patients with Colon Cancer

\begin{tabular}{lccc}
\hline & \multicolumn{2}{c}{ P-cadherin } & \\
\cline { 2 - 3 } & Negative & Positive & $P$ value \\
\hline $\begin{array}{c}\text { Sex, male:female } \\
\text { (no.) }\end{array}$ & $31: 18$ & $86: 67$ & 0.796 \\
Age, mean \pm SD & $57.2 \pm 11.4$ & $54.0 \pm 14.3$ & 0.384 \\
$\quad$ (years) & & & \\
Tumor size, mean \pm & $5.45 \pm 4.45$ & $5.34 \pm 2.35$ & 0.789 \\
$\quad$ SD (cm) & & & \\
Differentiation (no.) & & & 0.567 \\
Well & 5 & 19 & \\
Moderate & 37 & 120 & \\
Poor & 7 & 14 & \\
Depth of invasion & & & 0.578 \\
$\quad$ (no.) & & & \\
T1 + T2 & 8 & 15 & \\
T3 & 7 & 30 & \\
T4 & 34 & 108 & \\
Lymph node & & & 0.56 \\
involvement (no.) & & & \\
N0 & 19 & 48 & \\
N1 & 17 & 54 & \\
N2 & 13 & 51 & $0.027^{*}$ \\
Liver metastasis (no.) & & & \\
M0 & 30 & 66 & \\
M1 & 19 & 87 & \\
\hline
\end{tabular}

Pearson's chi-square test was used to define statistical significance. ${ }^{\star} P<0.05$. 

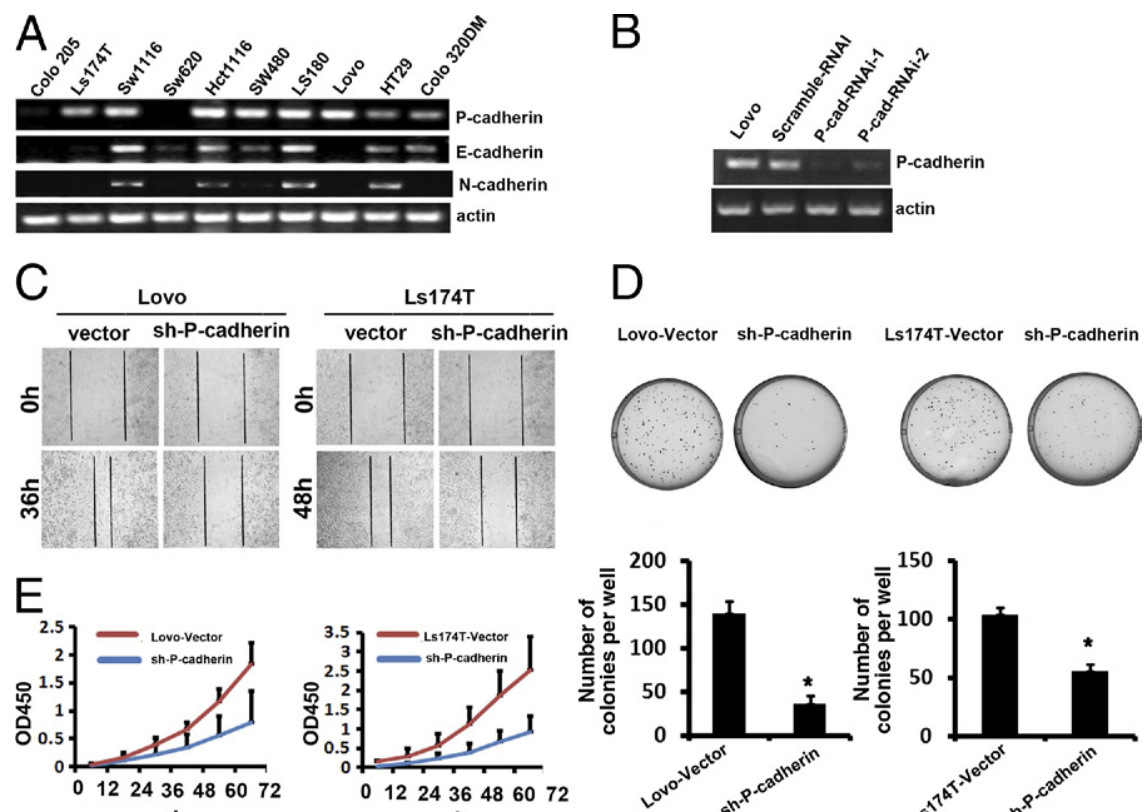

h
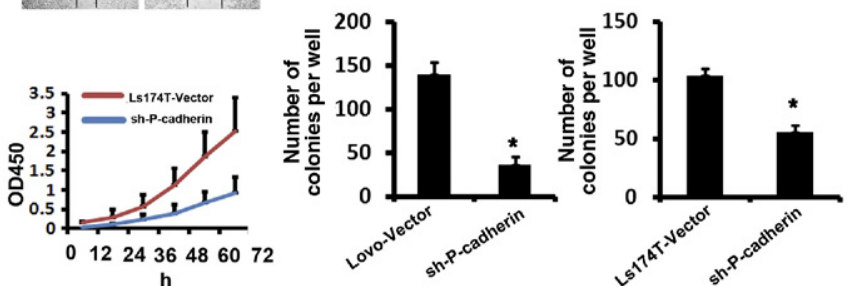

Figure 2. P-cadherin regulates the migration, proliferation, and colony formation of LoVo and Ls174T cells. A: P-cadherin expression in 10 colon cancer cell lines. B: Analysis of P-cadherin expression in LoVo cells. The P-cadherin mRNA level was examined by RT-PCR in transient transfected Pcadherin RNAi-1 and RNAi-2, scramble RNAi, and parental LoVo cells. P-cadherin RNAi-1 and RNAi-2 exhibited down-regulation of P-cadherin. C: $\mathrm{Mo}-$ tility of LoVo and Ls174T cells transfected with P-cadherin shRNA or vector cells was examined by wound-healing assay. Digital pictures were taken at 0,36, and 48 hours. D: LoVo and Ls174T cells transfected with P-cadherin shRNA or vector cells were grown for 14 days in semisolid soft agar medium to monitor anchorage-independent growth. Results are shown as means \pm SD E: LoVo and Ls174T cells transfected with Pcadherin shRNA or vector cells were seeded in 96-well plates for Cell Counting Kit-8 assay. Results are shown as means \pm SD. Statistical significance of ${ }^{*} P<0.05$, sh-P-cadherin group versus vector group. lent phenomenon and might play a key role in colon cancer progression. To avoid the effects of endogenous cadherin on P-cadherin function, we stably knocked down P-cadherin in LoVo and Ls174T colon cancer cells, which only express high levels of P-cadherin with extremely low levels of $\mathrm{E}$-cadherin and $\mathrm{N}$-cadherin expression, by shRNA. Two pair of oligonucleotides targeting sequences in the coding region of the P-cadherin gene, P-cadherin RNAi-1 and RNAi-2, were synthesized as shinterfering RNAs. Then, we transiently transfected LoVo with these vectors and examined the mRNA level of $\mathrm{P}$ cadherin at 48 hours. RT-PCR exhibited that P-cadherin RNAi-1 and RNAi-2 could dramatically suppress the expression of P-cadherin (Figure 2B).

\section{Reduced Expression of P-Cadherin Decreases Cell Motility in Colon Cancer Cells}

Wound-healing assays showed that P-cadherin shRNA cells migrated much more slowly than did vector and parental cells. Thirty-six hours after wounding, vector and parental LoVo cells became confluent, whereas LoVo P-cadherin shRNA cells migrated approximately a four-cell distance. Similarly, knockdown of P-cadherin also decreased migration in Ls174T cells (Figure 2C). These experiments were repeated three times, and the results were similar.

\section{Knockdown of P-Cadherin Expression in Colon Cancer Cells Inhibits Proliferation and Colony Formation}

Previous data have shown that ectopic expression of $\mathrm{P}$-cadherin is common in primary colon cancer tissues and is rare in normal tissues or restrictedly expressed in the basal cells representing the proliferative compartment of the epithelium. ${ }^{24,25}$ Therefore, we investigated whether P-cadherin expression has a causal role in tumor progression by colony-forming assay. The results showed that the colony-forming activity of LoVo and Ls174T P-cadherin shRNA cells under anchorage-independent conditions was markedly decreased compared with vector and parental cells in soft agar assay (Figure 2D). Given the importance of proliferation in the regulation of neoplastic transformation, we tested whether inhibiting the expression of P-cadherin in LoVo and Ls174T cells could affect cell growth by Cell Counting Kit-8 assay. The result showed that LoVo P-cadherin shRNA cells grow at a rate $40 \%$ slower than control cells. Consistently, down-regulation of P-cadherin in Ls174T cells also reduced the proliferation of Ls174T, and the inhibitory rate was approximately $50 \%$ (Figure $2 \mathrm{E}$ ). Together, these results indicate that $\mathrm{P}$-cadherin might play an important role in the regulation of cellular transformation and, thus, potentially contribute to the phenotype of metastasis.

\section{Knockdown of P-Cadherin Expression in Colon Cancer Cells Inhibits Growth and Invasive Properties in Nude Mice}

To determine whether P-cadherin expression has a causal role in tumor growth and invasion, we subcutaneously injected cells (LoVo P-cadherin shRNA cells, vector cells or Ls174T P-cadherin shRNA cells, vector cells) into athymic mice. After 43 days, the mice were sacrificed. The result showed that down-regulation of P-cadherin in colon cancer cells strongly inhibited tumor growth (Figure $3 A$ ). H\&E staining of tumor margins confirmed the invasive growth patterns into the surrounding muscles in the vector cells, whereas in the LoVo P-cadherin shRNA 

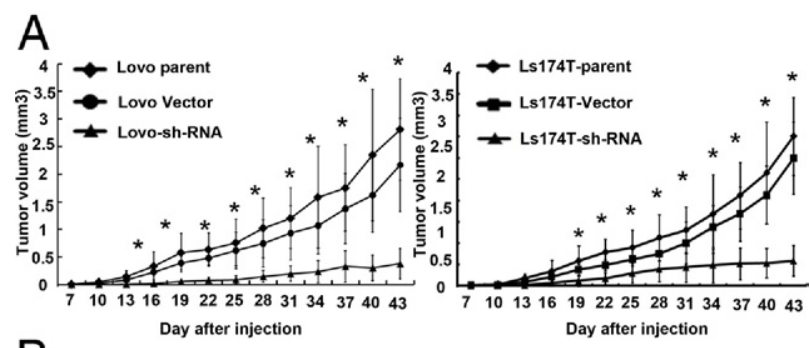

B

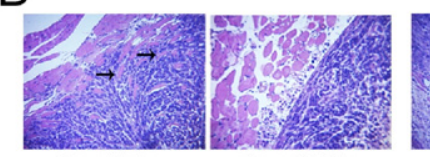

$\mathrm{C}$

Lovo-sh-RNA

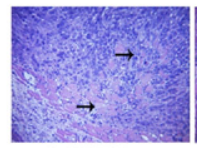

Ls174T Vector
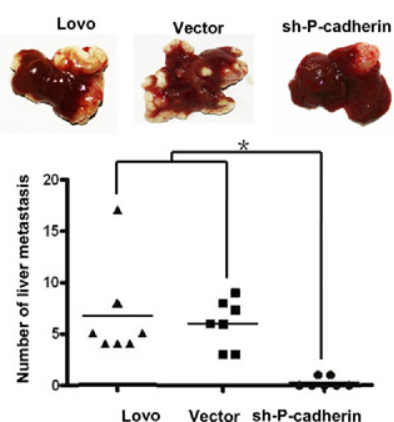

Figure 3. P-cadherin down-regulation significantly decreased tumor growth, tumor cell invasion into surrounding tissues, and liver metastasis. A: Tumor growth curves of LoVo and Ls174T and P-cadherin knockdown cells. Results are shown as means \pm SD. B: H\&E staining of vector groups and P-cadherin shRNA groups. The xenograft tumor showed a low invasive pattern in the P-cadherin shRNA groups. Arrows indicate area of muscular invasion. C: Down-regulation of P-cadherin in colon cancer cells dramatically inhibited the ability of the cells to generate tumor metastasis in the liver via intrasplenic injection in nude mice. Statistical plots of liver metastasis foci. Results are shown as means $\pm \mathrm{SD}$. Statistical significance of ${ }^{*} P<0.05$, sh-P-cadherin group versus vector or Lovo group.

cells, the xenograft tumor showed a low invasive pattern. Similar results were obtained in Ls174T P-cadherin shRNA cells and vector cells. Therefore, P-cadherin down-regulation significantly decreased tumor cell invasion into surrounding tissues (Figure 3B).

\section{Down-Regulation of P-Cadherin in Colon Cancer Cells Potently Decreases Liver Metastases in Nude Mice}

The previous results indicate that P-cadherin might contribute to colon cancer liver metastasis, so we further investigated whether inhibition of P-cadherin in colon cancer cells would affect liver metastasis. Note that the colon cancer cell lines LoVo and Ls174T displayed similar biologic behaviors and cadherin expression patterns. Therefore, nude mice were intrasplenically injected with either LoVo P-cadherin shRNA or vector cells. Eight weeks after splenic injection, all the mice were euthanized and underwent autopsy, and surface liver metastases were assessed. The results showed that the number of surface tumor foci in livers of mice injected with LoVo P-cadherin shRNA cells was significantly reduced compared with that in the control group. Incidence of liver metastases was detectable in seven of seven of LoVo vector cells, whereas two of seven mice injected with LoVo P-cadherin shRNA cells had detectable liver metastases (Figure 3C). Meanwhile, histologic examination of liver sections stained with $H \& E$ confirmed that the number of tumor foci in livers of mice injected with LoVo P-cadherin shRNA cells was significantly reduced compared with that in the control group. No visible or microscopic metastases were detected in the other organs of the mice. The results confirm that down-regulation of $\mathrm{P}$-cadherin in colon cancer cells strongly reduces cancer metastatic growth in vivo, supporting a critical role for P-cadherin in hepatic metastasis of colon cancer cells.
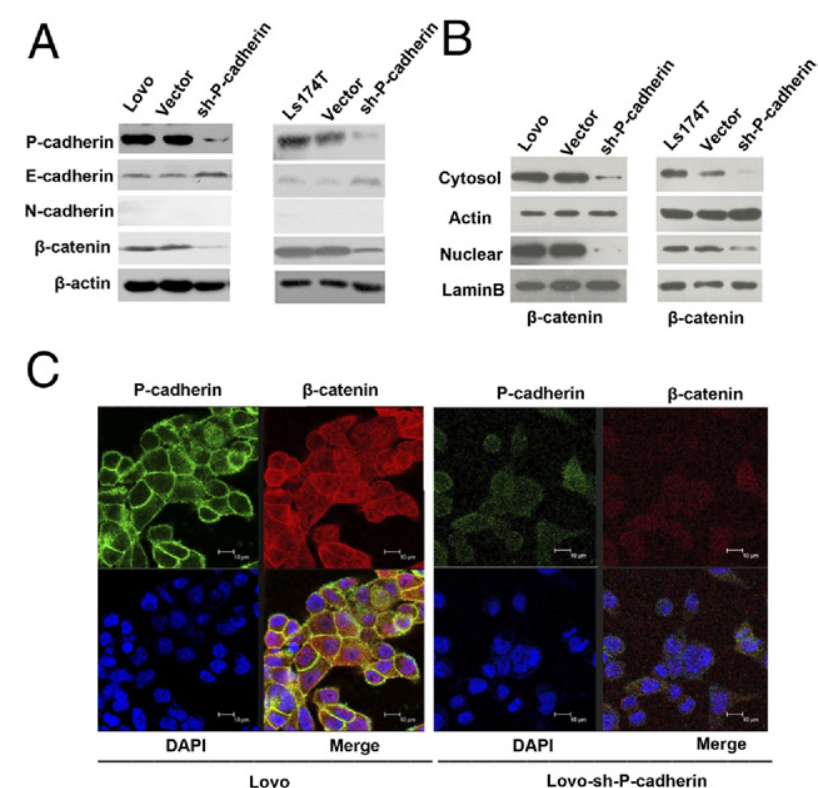

D
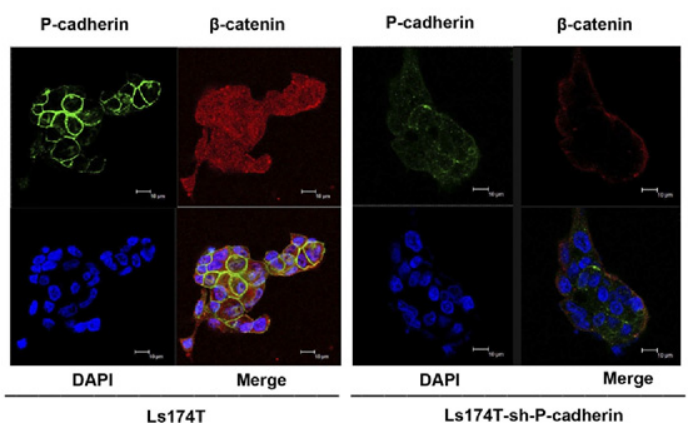

Figure 4. Association of P-cadherin expression with E-cadherin and $\beta$-catenin expression. A: Exogenous P-cadherin, E-cadherin, and N-cadherin were detected by Western blotting in two sets of LoVo and Ls174T cells transfected with P-cadherin shRNA or vector cells. B: The levels of nuclear and cytosol $\beta$-catenin were analyzed by Western blotting in two sets of LoVo and Ls174T cells transfected with P-cadherin shRNA or vector cells. C: Distribution of endogenous $\beta$-catenin in LoVo and LoVo P-cadherin shRNA cells analyzed by immunostaining using anti-P-cadherin antibody (green), $\beta$-catenin antibody (red), and DAPI (blue). In control cells, $\beta$-catenin was localized predominantly in the plasma or nuclear, but LoVo P-cadherin shRNA cells exhibited down-regulation of $\beta$-catenin from nuclear and cytoplasm. D: Distribution of endogenous $\beta$-catenin in Ls174T and Ls174T Pcadherin shRNA cells analyzed by immunostaining using anti-P-cadherin antibody (green), $\beta$-catenin antibody (red), and DAPI (blue). $\beta$-catenin was localized predominantly in the plasma or nuclear in Ls174T cells, but in Ls174T P-cadherin shRNA cells the staining of $\beta$-catenin was greatly reduced. 


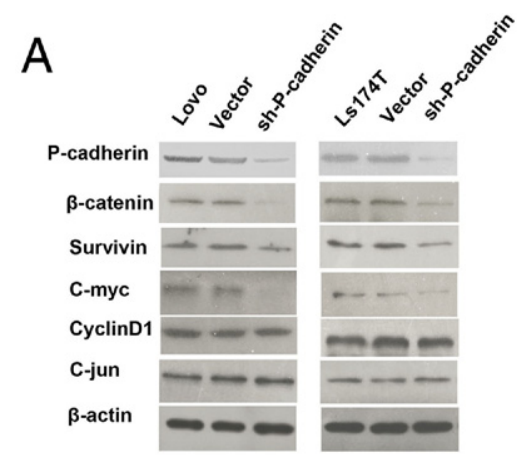

C

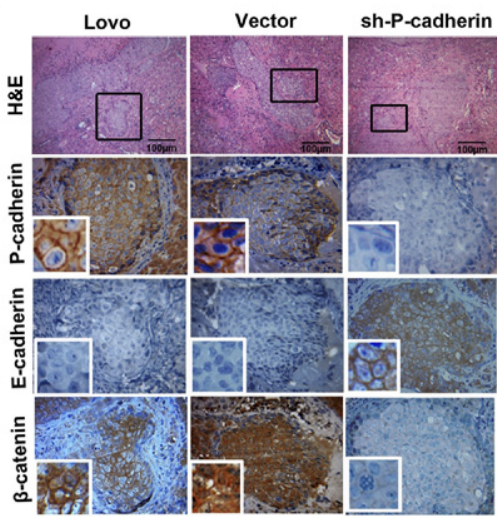

B

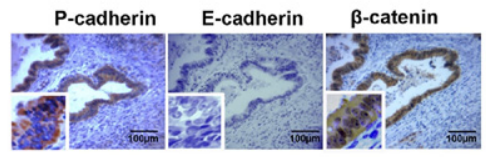

Figure 5. $\mathrm{P}$-cadherin activated the $\mathrm{Wnt} / \beta$-catenin pathway and inhibited the expression of E-cadherin. A: Levels of c-Myc, survivin, cyclin D1, and c-jun were analyzed by Western blotting in LoVo P-cadherin shRNA, Ls174T P-cadherin shRNA, and control cells. B: IHC study of the expression of P-cadherin, E-cadherin, and $\beta$-catenin in primary colon cancer tissues. The expression pattern of related molecules is shown in insets. C: IHC analysis of P-cadherin, E-cadherin, and $\beta$-catenin expression in experimental liver metastatic tissues. Magnification of tissues is shown in the black frames. The expression pattern of related molecules is shown in the insets. D: Immunoblot analysis of P-cadherin, E-cadherin, and EMT-related molecules in LoVo P-cadherin shRNA, Ls174T Pcadherin shRNA, and control cells.

\section{Inhibition of P-Cadherin in Colon Cancer Cells Leads to Down-Regulation of $\beta$-Catenin and Up-Regulation of E-Cadherin}

Several studies have shown that cadherin switching is associated with tumor progression and metastatic diseases. ${ }^{23,26}$ Therefore, we used Western blot analysis to detect whether silence of P-cadherin could affect endogenous expression of $\mathrm{E}$-cadherin or $\mathrm{N}$-cadherin. In LoVo P-cadherin shRNA and Ls174t P-cadherin shRNA derivative clones, we found that down-regulation of $\mathrm{P}$-cadherin was coupled with high expression of $\mathrm{E}$ cadherin and that the expression of $\mathrm{N}$-cadherin could not be detected (Figure 4A). $\beta$-catenin, which could interact with the cytoplasmic tail of cadherins, is often misregulated in colon cancers. Therefore, we examined the expression of $\beta$-catenin in P-cadherin shRNA cells and vector cells by Western blot. Decreased expression of $\beta$-catenin was observed in LoVo P-cadherin shRNA and Ls174t-P-cadherin shRNA derivative clones compared with control cells. We also prepared cytoplasmic and nuclear fractions and immunoblotted them with an anti- $\beta$-catenin antibody. The nuclear and cytoplasmic expression of $\beta$-catenin was lower in $\mathrm{P}$ cadherin shRNA cells than in parent cells (Figure 4B). The expression patterns of E-cadherin, P-cadherin, and $\beta$-catenin were also proved by immunofluorescence staining (Figure $4, C$ and $D$ ). To further determine the effects of changes in $\beta$-catenin activity, we examined the expression of c-Myc, survivin, cyclin D1, and $\mathrm{c}$-jun, which are known target genes for $\mathrm{Wnt} / \beta$ catenin signaling in LoVo and Ls174T cell lines with genetically altered P-cadherin expression. Consistent with the Wnt/ $\beta$-catenin activities, expression of survivin and c-Myc was decreased with inhibition of P-cadherin in LoVo and Ls174T cells, and there were no changes in cyclin D1 and C-jun expression compared with in control cells (Figure 5A).

Based on these observations, we examined whether there was a correlation between P-cadherin, E-cadherin, and nuclear $\beta$-catenin in 67 colon cancer tissues with different $P$-cadherin immunostaining scores, including 2 cases for "0," 16 cases for " 1, " 13 cases for "2," and 36 cases for " 3 " (Figure 5B and Table 3). Correlation analysis among expression of P-cadherin, E-cadherin, and nuclear $\beta$-catenin staining using Spearman's rho test revealed a significant correlation between $\mathrm{P}$-cadherin and nuclear $\beta$-catenin staining (Spearman rho $=0.439)$ and an inverse correlation between $\mathrm{P}$-cadherin and E-cadherin (Spearman rho $=0.642 ; P<0.01$ ) (see Supplemental Table S1 at $h$ ttp://ajp.amjpathol.org). Furthermore, a nuclear $\beta$-catenin staining pattern was significantly correlated with liver metastasis and depth of invasion (Table 4). Next, we collected liver metastatic tissues from experimental liver metastasis by intrasplenic inoculation and assessed the expression of P-cadherin, $\beta$-catenin, and E-cadherin. As expected, we found that the expression of P-cadherin was hardly detected and that the expression of E-cadherin was highly expressed coupled with downregulation with $\beta$-catenin (Figure $5 \mathrm{C}$ ). These studies suggest that $\mathrm{P}$-cadherin may play important roles in the metastasis of colon cancer to the liver by cadherin switching and up-regulation of $\beta$-catenin expression. 
Table 3. Association between the Expression of E-Cadherin, P-Cadherin, and Nuclear $\beta$-Catenin

\begin{tabular}{|c|c|c|c|c|c|c|c|c|}
\hline \multirow[b]{2}{*}{ Staining score } & \multicolumn{4}{|c|}{ E-cadherin staining score } & \multirow[b]{2}{*}{$P$ value } & \multicolumn{2}{|c|}{$\begin{array}{c}\text { Nuclear } \\
\beta \text {-catenin } \\
\text { staining score } \\
\end{array}$} & \multirow[b]{2}{*}{$P$ value } \\
\hline & 0 & 1 & 2 & 3 & & 0 & 1 & \\
\hline P-cadherin & & & & & $0.014^{*}$ & & & $0.005^{*}$ \\
\hline 0 & 2 & 0 & 0 & 0 & & 2 & 0 & \\
\hline 1 & 10 & 5 & 1 & 0 & & 11 & 5 & \\
\hline 2 & 6 & 7 & 0 & 0 & & 11 & 2 & \\
\hline 3 & 5 & 20 & 9 & 2 & & 13 & 23 & \\
\hline E-cadherin & & & & & & & & $0.000^{\star}$ \\
\hline 0 & & & & & & 20 & 3 & \\
\hline 1 & & & & & & 15 & 17 & \\
\hline 2 & & & & & & 2 & 8 & \\
\hline 3 & & & & & & 0 & 2 & \\
\hline
\end{tabular}

Pearson's chi-square test was used to define statistical significance. ${ }^{*} P<0.05$.

\section{Discussion}

This study was undertaken to understand the important roles of P-cadherin in colon cancer liver metastasis. cDNA microarray analysis showed that P-cadherin was up-regulated in liver metastasis samples compared with primary colon cancer samples. We also assessed the expression of P-cadherin in 30 primary colon cancer samples and paired liver metastasis samples and found that the level of P-cadherin in the hepatic metastases was significantly higher than that in the matched primary coIon cancer tissue by immunochemical analysis. Moreover, we evaluated the expression of P-cadherin in car-

Table 4. Association between $\beta$-Catenin Nuclear Staining and Clinicopathologic Characteristics of the 67 Patients with Colon Cancer

\begin{tabular}{|c|c|c|c|}
\hline \multirow[b]{2}{*}{ Variable } & \multicolumn{3}{|c|}{ Nuclear $\beta$-catenin score } \\
\hline & 0 & 1 & $P$ value \\
\hline $\begin{array}{l}\text { Sex, male:female } \\
\text { (no.) }\end{array}$ & $20: 17$ & $23: 7$ & 0.096 \\
\hline $\begin{array}{l}\text { Age, mean } \\
\text { (years) }\end{array}$ & $54.6 \pm 11.8$ & $55.7 \pm 11$ & 0.651 \\
\hline $\begin{array}{l}\text { Tumor size, mean } \pm \\
\text { SD }(\mathrm{cm})\end{array}$ & $5.12 \pm 2.28$ & $5.28 \pm 1.28$ & 0.12 \\
\hline Differentiation (no.) & & & 0.417 \\
\hline Well & 8 & 6 & \\
\hline Moderate & 2 & 0 & \\
\hline Poor & 27 & 24 & \\
\hline $\begin{array}{l}\text { Depth of invasion } \\
\text { (no.) }\end{array}$ & & & $0.019^{*}$ \\
\hline $\mathrm{T} 1+\mathrm{T} 2$ & 8 & 2 & \\
\hline T3 & 5 & 7 & \\
\hline T4 & 24 & 21 & \\
\hline $\begin{array}{l}\text { Lymph node } \\
\quad \text { metastasis (no.) }\end{array}$ & & & 0.899 \\
\hline NO & 13 & 11 & \\
\hline N1 & 11 & 10 & \\
\hline N2 & 13 & 9 & \\
\hline $\begin{array}{l}\text { Liver metastasis } \\
\qquad(\text { no.) }\end{array}$ & & & $0.001^{*}$ \\
\hline MO & 24 & 7 & \\
\hline M1 & 13 & 23 & \\
\hline
\end{tabular}

Pearson's chi-square test was used to define statistical significance. ${ }^{*} P<0.05$. cinoma TMA containing 202 primary colon tumors that had clinical follow-up records. The result also demonstrated that the expression of P-cadherin was correlated with liver metastasis $(P<0.05)$ and was coupled with shorter overall survival. These data, for the first time, imply that P-cadherin has distinct roles in colon cancer liver metastasis and is worthy of further investigation.

Cadherins could maintain the mucosal integrity and are central to the development of the gastrointestinal tract, ${ }^{27}$ although it has been reported that aberrant expression of cadherins might contribute to carcinogenesis and metastasis in several tumor types. For example, cadherin-11 could promote the metastasis of prostate cancer cells to bone. ${ }^{28}$ VE-cadherin could facilitate breast cancer cell metastasis by enhancing transendothelial migration. ${ }^{29}$ Moreover, a variety of recent publications have indicated that ectopic expression of P-cadherin could play complicated roles in cancer development. For one thing, P-cadherin is ectopically expressed early in colon cancer and persists during invasive cancer. ${ }^{24,30}$ For another, P-cadherin acts as a proadhesive and anti-invasive/antimigratory molecule in colon carcinoma cells and was significantly associated with a higher tumor grade. ${ }^{31}$ By contrast, little is known about whether changes in P-cadherin expression represent important roles in hepatic metastasis.

The importance of P-cadherin as a regulator of colon cancer liver metastasis is evident from studies involving in vitro genetic manipulation of P-cadherin in colon cancer cells and from in vivo nude mice studies. We first evaluated the expression of E-cadherin, P-cadherin, and $\mathrm{N}$-cadherin in 10 colon cancer cells and found that the levels of P-cadherin mRNA in 8 of 10 cell lines, excluding Colo320DM and SW620, were relatively overexpressed rather than E-cadherin or $\mathrm{N}$-cadherin. Previous studies also reported that $\mathrm{P}$-cadherin could inhibit HT29 colon cancer cell migration, ${ }^{31}$ which simultaneously express E-cadherin, $\mathrm{N}$-cadherin, and P-cadherin. To minimize the interruption of endogenous cadherin, we selected LoVo and Ls174T colon carcinoma cells, which express Pcadherin only, to study the function of P-cadherin. As mentioned in Results, we stably knocked down its expres- 
sion using shRNA in LoVo and Ls174T cells and found that down-regulation of P-cadherin significantly decreased migration, proliferation, and colony formation in soft agar. Furthermore, down-regulation of P-cadherin in colon cancer cells strongly inhibited tumor growth into the surrounding tissues and formation of liver metastases compared with control cells. Such events, for the first time, suggest a role for P-cadherin in colon cancer liver metastasis.

How can P-cadherin affect tumor cell behavior? The answer may well lie in its capacity to down-regulate Ecadherin and promote $\beta$-catenin signaling in tumor cells. For one thing, down-regulation of E-cadherin is a hallmark of epithelial-mesenchymal transition (EMT); therefore, we analyzed the EMT-associated genes, including snail, slug, twist, and vimentin, in parent and P-cadherin shRNA cells using Western blotting. The results demonstrate that the expression of vimentin and slug could not be detected, and there was no significantly changed expression of snail and twist in LoVo or Ls174T and P-cadherin knockdown cells. The results indicate that P-cadherin regulates cell migration or invasion through EMT-independent signaling in colon cancer cells (Figure 5D). Recent studies also reported that p120-catenin had a significant effect on the type of cadherin expressed. ${ }^{32}$ Then we detected the expression of p120-catenin in the parent and knockdown cells using immunofluorescence and Western blotting. The results show that there is no difference in the expression pattern or level between LoVo or Ls174T and knockdown cells (Figure 5D; see also Supplemental Figure S1 at http://ajp.amjpathol.org). It remains unclear how P-cadherin affects the expression of E-cadherin. For another, $\beta$-catenin has been implicated in signaling events leading to EMT and metastasis, $^{33,34}$ which accumulates in the cytoplasm and migrates to the nucleus, activating other genes involved in carcinogenesis, such as c-Myc, cyclin D1, c-jun, and survivin. Thus, we evaluated the expression of $\beta$-catenin and its downstream target molecules in LoVo and Ls174T cell lines with or without P-cadherin knockdown. Consistent with the $\mathrm{Wnt} / \beta$-catenin activities, P-cadherin knockdown in LoVo and Ls174T cells resulted in a decrease in the expression of survivin and c-Myc, whereas there was no change in cyclin D1 and c-jun. It has been reported that c-Myc is overexpressed in many kinds of cancer and could provide constitutive signals that promote cellular transformation and control cell proliferation and apoptosis. ${ }^{35}$ Survivin is the member of the inhibitor of apoptosis gene family that counteracts cell death. In patients with colorectal cancer, expression of survivin has been associated with poor outcome, abbreviated survival, and decreased tumor cell apoptosis in vivo. ${ }^{36,37}$

We also studied the expression of E-cadherin, P-cadherin, and $\beta$-catenin in the same tissue samples by $\mathrm{IHC}$ analysis. We found that increased P-cadherin expression was significantly associated with reduced E-cadherin and increased $\beta$-catenin expression. Consistent with expression in human tissues, we found that down-regulation of $\mathrm{P}$-cadherin was concomitant with up-regulation of $\mathrm{E}$ cadherin and down-regulation with $\beta$-catenin in experimental liver metastatic foci tissues. Consequently, we speculate that the role of $\mathrm{P}$-cadherin in colon cancer liver metastasis may be a result of the "cadherin switch" in tumor progression, which represents an important transition point in tumor progression. ${ }^{38,39}$ For one thing, loss of E-cadherin is well known as a key signal for epithelial to mesenchymal transition in tumor cells. ${ }^{40,41}$ Decreased expression of E-cadherin is associated with increased motility and invasiveness. In addition to down-regulation of E-cadherin by P-cadherin, we also found that P-cadherin could up-regulate the expression of $\beta$-catenin protein. Increased $\beta$-catenin expression plays a well-characterized dual role in cell adhesion and signal transduction, which is correlated with oncogenic transformation and cell proliferation. ${ }^{42-44}$

Overall, the present study may have a variety of implications for understanding the role of P-cadherin in metastasis of colon cancer to the liver. First, this is the first study showing the expression of P-cadherin in the liver metastases of colon cancer and revealing that P-cadherin overexpression is significantly associated with metastasis and clinical stage in patients with colon cancer. Second, we showed that P-cadherin promotes migration, proliferation, and metastasis of colon cancer cells by down-regulating E-cadherin expression coupled with upregulation of $\beta$-catenin expression and its downstream target molecules, including survivin and c-Myc. Other mechanisms in P-cadherin relevant to the alteration of classical cadherin expression, cadherin-catenin interaction has yet to be elucidated. However, the present observations raise the possibility that $\mathrm{P}$-cadherin may be a promising candidate for targeted therapy of colon cancer and liver metastasis.

\section{References}

1. Wicherts DA, de Haas RJ, Borel Rinkes IH, Voest EE, van Hillegersberg R: Better treatment for patients with colorectal liver metastases. Ned Tijdschr Geneeskd 2006, 150:345-351

2. Ochiai $H$, Nakanishi $Y$, Fukasawa $Y$, Sato $Y$, Yoshimura K, Moriya $Y$, Kanai Y, Watanabe M, Hasegawa H, Kitagawa Y, Kitajima M, Hirohashi S: A new formula for predicting liver metastasis in patients with colorectal cancer: immunohistochemical analysis of a large series of 439 surgically resected cases. Oncology 2008, 75:32-41

3. Bakalakos EA, Kim JA, Young DC, Martin EW Jr: Determinants of survival following hepatic resection for metastatic colorectal cancer. World J Surg 1998, 22:399-404

4. Choti MA, Sitzmann JV, Tiburi MF, Sumetchotimetha W, Rangsin R, Schulick RD, Lillemoe KD, Yeo CJ, Cameron JL: Trends in long-term survival following liver resection for hepatic colorectal metastases. Ann Surg 2002, 235:759-766

5. Bos PD, Zhang XHF, Nadal C, Shu W, Gomis RR, Nguyen DX, Minn AJ, van de Vijver MJ, Gerald WL, Foekens JA, Massague J: Genes that mediate breast cancer metastasis to the brain. Nature 2009, 459:1005-1009

6. Minn AJ, Gupta GP, Siegel PM, Bos PD, Shu W, Giri DD, Viale A, Olshen AB, Gerald WL, Massague J: Genes that mediate breast cancer metastasis to lung. Nature 2005, 436:518-524

7. Smith SC, Nicholson B, Nitz M, Frierson HF Jr, Smolkin M, Hampton G, El-Rifai W, Theodorescu D: Profiling bladder cancer organ site-specific metastasis identifies LAMC2 as a novel biomarker of hematogenous dissemination. Am J Pathol 2009, 174:371-379

8. Ben-Ze'ev A, Geiger B: Differential molecular interactions of $\beta$-catenin and plakoglobin in adhesion, signaling and cancer. Curr Opin Cell Biol 1998, 10:629-639 
9. Drees F, Pokutta S, Yamada S, Nelson WJ, Weis WI: $\alpha$-Catenin is a molecular switch that binds E-cadherin- $\beta$-catenin and regulates actin-filament assembly. Cell 2005, 123:903-915

10. Jankowski JA, Bruton R, Shepherd N, Sanders DS: Cadherin and catenin biology represent a global mechanism for epithelial cancer progression. Mol Pathol 1997, 50:289-290

11. Hibi K, Goto T, Mizukami H, Kitamura YH, Sakuraba K, Sakata M, Saito M, Ishibashi K, Kigawa G, Nemoto H, Sanada Y: Demethylation of the $\mathrm{CDH} 3$ gene is frequently detected in advanced colorectal cancer. Anticancer Res 2009, 29:2215-2217

12. Hibi K, Kitamura YH, Mizukami H, Goto T, Sakuraba K, Sakata M Saito M, Ishibashi K, Kigawa G, Nemoto H, Sanada Y: Frequent CDH3 demethylation in advanced gastric carcinoma. Anticancer Res 2009, 29:3945-3947

13. Paredes J, Albergaria A, Oliveira JT, Jeronimo C, Milanezi F, Schmitt FC: P-cadherin overexpression is an indicator of clinical outcome in invasive breast carcinomas and is associated with $\mathrm{CDH} 3$ promoter hypomethylation. Clin Cancer Res 2005, 11:5869-5877

14. Taniuchi K, Nakagawa H, Hosokawa M, Nakamura T, Eguchi H, Ohigashi $\mathrm{H}$, Ishikawa $\mathrm{O}$, Katagiri T, Nakamura Y: Overexpressed P-cadherin/CDH3 promotes motility of pancreatic cancer cells by interacting with p120ctn and activating rho-family GTPases. Cancer Res 2005, 65:3092-3099

15. Mandeville JA, Silva Neto B, Vanni AJ, Smith GL, Rieger-Christ KM, Zeheb R, Loda M, Libertino JA, Summerhayes IC: P-cadherin as a prognostic indicator and a modulator of migratory behaviour in bladder carcinoma cells. BJU Int 2008, 102:1707-1714

16. Hu H, Sun L, Guo C, Liu Q, Zhou Z, Peng L, Pan J, Yu L, Lou J, Yang Z, Zhao P, Ran Y: Tumor cell-microenvironment interaction models coupled with clinical validation reveal CCL2 and SNCG as two predictors of colorectal cancer hepatic metastasis. Clin Cancer Res 2009, 15:5485-5493

17. Patterson TA, Lobenhofer EK, Fulmer-Smentek SB, Collins PJ, Chu T-M, Bao W, Fang H, Kawasaki ES, Hager J, Tikhonova IR, Walker SJ, Zhang L, Hurban P, de Longueville F, Fuscoe JC, Tong W, Shi L, Wolfinger RD: Performance comparison of one-color and two-color platforms within the Microarray Quality Control (MAQC) project. Nat Biotech 2006, 24:1140-1150

18. Guo Y, Guo H, Zhang L, Xie H, Zhao X, Wang F, Li Z, Wang Y, Ma S, Tao J, Wang W, Zhou Y, Yang W, Cheng J: Genomic analysis of anti-hepatitis B virus (HBV) activity by small interfering RNA and lamivudine in stable HBV-producing cells. J Virol 2005, 79:1439214403

19. Thakur A, Bollig A, Wu J, Liao DJ: Gene expression profiles in primary pancreatic tumors and metastatic lesions of Ela-c-myc transgenic mice. Mol Cancer 2008, 7:11

20. Lee CC, Lee MS, Ho HC, Hung SK, Tung YT, Chou P, Su YC: The prognostic utility of haptoglobin genotypes in squamous cell carcinoma of the head and neck. Clin Chem Lab Med 2009, 47:1277-1283

21. Fritz $P$, Behrle E, Beaune P, Eichelbaum M, Kroemer HK: Differential expression of drug metabolizing enzymes in primary and secondary liver neoplasm: immunohistochemical characterization of cytochrome P4503A and glutathione-S-transferase. Histochemistry 1993, 99:443-451

22. Pyo SW, Hashimoto $M$, Kim YS, Kim CH, Lee SH, Johnson KR, Wheelock MJ, Park JU: Expression of E-cadherin, P-cadherin and $\mathrm{N}$-cadherin in oral squamous cell carcinoma: correlation with the clinicopathologic features and patient outcome. J Craniomaxillofac Surg 2007, 35:1-9

23. Jager T, Becker M, Eisenhardt A, Tilki D, Totsch M, Schmid KW, Romics I, Rubben H, Ergun S, Szarvas T: The prognostic value of cadherin switch in bladder cancer. Oncol Rep 23:1125-1132

24. Milicic A, Harrison LA, Goodlad RA, Hardy RG, Nicholson AM, Presz M, Sieber O, Santander S, Pringle JH, Mandir N, East P, Obszynska J, Sanders S, Piazuelo E, Shaw J, Harrison R, Tomlinson IP, McDonald SA, Wright NA, Jankowski JA: Ectopic expression of P-cadherin correlates with promoter hypomethylation early in colorectal carcinogenesis and enhanced intestinal crypt fission in vivo. Cancer Res 2008, 68:7760-7768
25. Williams HK, Sanders DS, Jankowski JA, Landini G, Brown AM: Expression of cadherins and catenins in oral epithelial dysplasia and squamous cell carcinoma. J Oral Pathol Med 1998, 27:308-317

26. Gravdal K, Halvorsen OJ, Haukaas SA, Akslen LA: A switch from $\mathrm{E}$-cadherin to $\mathrm{N}$-cadherin expression indicates epithelial to mesenchymal transition and is of strong and independent importance for the progress of prostate cancer. Clinical Cancer Res 2007, 13:70037011

27. Takeichi M: Cadherin cell adhesion receptors as a morphogenetic regulator. Science 1991, 251:1451-1455

28. Chu K, Cheng CJ, Ye X, Lee YC, Zurita AJ, Chen DT, Yu-Lee LY, Zhang S, Yeh ET, Hu MC, Logothetis CJ, Lin SH: Cadherin-11 promotes the metastasis of prostate cancer cells to bone. Mol Cancer Res 2008, 6:1259-1267

29. Sahni A, Arevalo MT, Sahni SK, Simpson-Haidaris PJ: The VE-cadherin binding domain of fibrinogen induces endothelial barrier permeability and enhances transendothelial migration of malignant breast epithelial cells. Int J Cancer 2009, 125:577-584

30. Hardy RG, Tselepis C, Hoyland J, Wallis Y, Pretlow TP, Talbot I, Sanders DSA, Matthews G, Morton D, Jankowski JAZ: Aberrant Pcadherin expression is an early event in hyperplastic and dysplastic transformation in the colon. Gut 2002, 50:513-519

31. Van Marck V, Stove C, Jacobs K, Van den Eynden G, Bracke M: $\mathrm{P}$-cadherin in adhesion and invasion: opposite roles in colon and bladder carcinoma. Int J Cancer 2011, 128:1031-1044

32. Cheung LW, Leung PC, Wong AS: Cadherin switching and activation of p120 catenin signaling are mediators of gonadotropin-releasing hormone to promote tumor cell migration and invasion in ovarian cancer. Oncogene 2010, 29:2427-2440

33. Hugh TJ, Dillon SA, O'Dowd G, Getty B, Pignatelli M, Poston GJ, Kinsella AR: $\beta$-Catenin expression in primary and metastatic colorectal carcinoma. Int J Cancer 1999, 82:504-511

34. Zhang W, Jiang B, Guo Z, Sardet C, Zou B, Lam CS, Li J, He M, Lan HY, Pang R, Hung IF, Tan VP, Wang J, Wong BC: Four-and-a-half LIM protein 2 promotes invasive potential and epithelial-mesenchymal transition in colon cancer. Carcinogenesis 2010, 31:1220-1229

35. Grandori C, Cowley SM, James LP, Eisenman RN: The Myc/Max/Mad network and the transcriptional control of cell behavior. Annu Rev Cell Dev Biol 2000, 16:653-699

36. Kim PJ, Plescia J, Clevers H, Fearon ER, Altieri DC: Survivin and molecular pathogenesis of colorectal cancer. Lancet 2003, 362 : 205-209

37. Zhang M, Coen JJ, Suzuki Y, Siedow MR, Niemierko A, Khor LY, Pollack A, Zhang Y, Zietman AL, Shipley WU, Chakravarti A: Survivin is a potential mediator of prostate cancer metastasis. Int J Radiat Oncol Biol Phys 2010, 78:1095-1103

38. Maeda M, Johnson KR, Wheelock MJ: Cadherin switching: essential for behavioral but not morphological changes during an epitheliumto-mesenchyme transition. J Cell Sci 2005, 118:873-887

39. Cheung LWT, Leung PCK, Wong AST: Cadherin switching and activation of p120 catenin signaling are mediators of gonadotropinreleasing hormone to promote tumor cell migration and invasion in ovarian cancer. Oncogene 29:2427-2440

40. Kemler R: From cadherins to catenins: cytoplasmic protein interactions and regulation of cell adhesion. Trends Genet 1993, 9:317-321

41. Nagafuchi A, Takeichi M: Cell binding function of E-cadherin is regulated by the cytoplasmic domain. EMBO J 1988, 7:3679-3684

42. Dolled-Filhart M, McCabe A, Giltnane J, Cregger M, Camp RL, Rimm DL: Quantitative in situ analysis of $\beta$-catenin expression in breast cancer shows decreased expression is associated with poor outcome. Cancer Res 2006, 66:5487-5494

43. Behrens J, von Kries JP, Kuhl M, Bruhn L, Wedlich D, Grosschedl R, Birchmeier W: Functional interaction of $\beta$-catenin with the transcription factor LEF-1. Nature 1996, 382:638-642

44. Cheah PY, Choo PH, Yao J, Eu KW, Seow-Choen F: A survivalstratification model of human colorectal carcinomas with $\beta$-catenin and p27kip1. Cancer 2002, 95:2479-2486 